\title{
A Case of Fever and Rash Following a Urinary Tract Infection
}

\author{
Harshita Jagwani ${ }^{1}$, Partha P Halder ${ }^{2}$, Priyankar Pal ${ }^{3}$, Mausami Mukherjee ${ }^{4}$, Debapoma Biswas ${ }^{5}$
}

\begin{abstract}
Drug reaction with eosinophilia and systemic symptoms (DRESS) syndrome is an uncommon life-threatening hypersensitivity drug reaction characterized by fever, rash, lymphadenopathy, and internal organ involvement occurring 2-8 weeks after the initiation of the offending drug. It is a clinical diagnosis and management involves the prompt withdrawal of the drug. We report a 2 years 7 months old child who presented with DRESS syndrome after the introduction of multiple antibiotics and improved after withdrawal of all the antibiotics and initiation of systemic corticosteroid.
\end{abstract}

Keywords: Drug reaction with eosinophilia and systemic symptoms syndrome, Hypersensitivity drug reaction, Systemic corticosteroid.

Pediatric Infectious Disease (2021): 10.5005/jp-journals-10081-1306

\section{BACKGROUND}

Drug reaction with eosinophilia and systemic symptoms (DRESS) syndrome is a drug-induced life-threatening hypersensitivity reaction with multisystem involvement including skin, lymph nodes, liver, kidney, and lungs. It has a $10 \%$ mortality rate which is mostly attributed to fulminant hepatitis. ${ }^{1}$ This type of reaction was first described in the 1940s after the introduction of hydantoin and its derivatives and the term DRESS was coined by Bocquet et al. ${ }^{2}$ The pathognomic feature of DRESS syndrome is organ dysfunction. ${ }^{2-4}$ Aromatic antiepileptics have been identified as the most common cause. With an estimated incidence of 1:1,000-1:10,000 drug exposures, ${ }^{5}$ DRESS syndrome is less prevalent in children when compared to adults and hence underdiagnosed by pediatricians. We hereby report a 2 years 7 months old child who presented with DRESS syndrome after the introduction of multiple antibiotics and recovered after the stoppage of antibiotics and initiation of systemic corticosteroid.

\section{Case Description}

A previously healthy 2 years 7 months old female received antibiotics piperacillin-tazobactam and amikacin for 10 days for an episode of urinary tract infection followed by cotrimoxazole as prophylaxis for grade IV vesicoureteric reflux. Seventeen days later, the child developed fever and rash which initially involved the face and later spread to the trunk, arms, and the whole body. The child was thereon taken to multiple local pediatricians as a result of which the child was initiated on multiple antibiotics consisting of piperacillin-tazobactam, amikacin, meropenem, doxycycline, azithromycin, and ceftriaxone. The urine culture report was normal.

On admission, the child was febrile with generalized edema, hepatomegaly, cervical and inguinal lymphadenopathy. An erythematous maculopapular non-blanching rash was present which later became confluent and increasingly pruritic in nature (Fig. 1). There was minimal oral mucosal involvement and decreased urine output.

Laboratory investigations revealed leukocytosis, eosinophilia, elevated liver enzymes, hypoalbuminemia, and elevated C-reactive protein as shown in Table 1. USG abdomen revealed ascites with hepatomegaly and chest X-ray showed infiltrates on the right side.

All antibiotics were discontinued and the child was initiated on IV dexamethasone after which oliguria and edema resolved.
1,2,4,5 Department of Pediatrics, Institute of Child Health, Kolkata, West Bengal, India

${ }^{3}$ Department of Pediatric Rheumatology, Institute of Child Health Kolkata, West Bengal, India

Corresponding Author: Harshita Jagwani, Department of Pediatrics, Institute of Child Health, Kolkata, West Bengal, India, Phone: +91 7406223348, e-mail: harshitajagwani10@gmail.com

How to cite this article: Jagwani $\mathrm{H}$, Halder PP, Pal $\mathrm{P}$, et al. A Case of Fever and Rash Following a Urinary Tract Infection. Pediatr Inf Dis 2021;3(4):163-164.

Source of support: Nil

Conflict of interest: None

The child was then shifted to oral prednisolone. Rash improved and the child was discharged after a week on prednisolone $2 \mathrm{mg} /$ $\mathrm{kg}$ which was gradually tapered and stopped.

\section{Discussion}

Drug reaction with eosinophilia and systemic symptoms syndrome is a type 4 delayed hypersensitivity reaction most

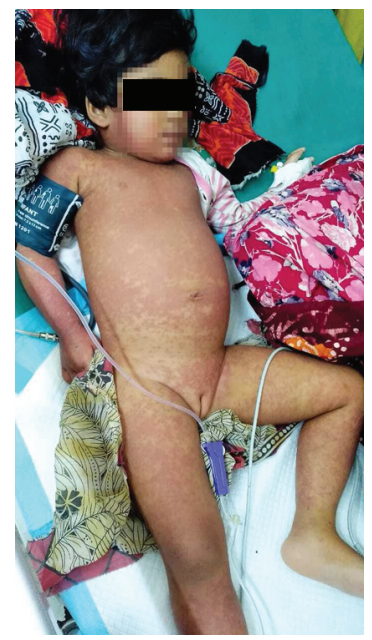

Fig. 1: Erythematous, non-blanching maculopapular rash present over the body on admission

(O) The Author(s). 2021 Open Access This article is distributed under the terms of the Creative Commons Attribution 4.0 International License (https://creativecommons. org/licenses/by-nc/4.0/), which permits unrestricted use, distribution, and non-commercial reproduction in any medium, provided you give appropriate credit to the original author(s) and the source, provide a link to the Creative Commons license, and indicate if changes were made. The Creative Commons Public Domain Dedication waiver (http://creativecommons.org/publicdomain/zero/1.0/) applies to the data made available in this article, unless otherwise stated. 
Table 1: Laboratory investigations of the child

\begin{tabular}{|c|c|c|c|c|}
\hline Day of illness & 13 & 14 & 18 & 24 \\
\hline & & On admission & & $\begin{array}{l}\text { On } \\
\text { discharge }\end{array}$ \\
\hline $\begin{array}{l}\text { WBC count } \\
\left(\text { cells } / \mathrm{mm}^{3} \text { ) }\right.\end{array}$ & 8,900 & 50,140 & 47,050 & 23,100 \\
\hline $\begin{array}{l}\text { Neutrophils } \\
\text { (cells } / \mathrm{mm}^{3} \text { ) }\end{array}$ & 5,874 & 15,242 & 23,383 & 11,088 \\
\hline $\begin{array}{l}\text { Eosinophils } \\
\text { (cells } / \mathrm{mm}^{3} \text { ) }\end{array}$ & 445 (5\%) & 19,103 (38\%) & 1,599 (3.4\%) & $0(0 \%)$ \\
\hline $\begin{array}{l}\text { Lymphocytes } \\
\text { (cells } / \mathrm{mm}^{3} \text { ) }\end{array}$ & 2,403 & 7,821 & 18,537 & 10,164 \\
\hline CRP (mg/dL) & & 72.5 & 6.1 & \\
\hline Albumin (g/dL) & & 2.9 & 3.4 & \\
\hline AST (U/L) & & 168 & 50 & \\
\hline $\operatorname{ALT}(\mathrm{U} / \mathrm{L})$ & & 197 & 97 & \\
\hline
\end{tabular}

commonly caused due to anticonvulsants. The pathogenesis has not completely been well understood but seems to include the following-deficiency or abnormality of epoxide hydroxylase enzyme causing accumulation of metabolites, reactivation of herpes virus family, genetic association with certain HLA alleles. ${ }^{6}$

Drug reaction with eosinophilia and systemic symptoms syndrome occurs 2-8 weeks after the initiation of the offending drug. Skin involvement can range from an urticarial, maculopapular eruption to vesicles, bullae, pustules, purpura, target lesions, facial edema, cheilitis, and erythroderma. ${ }^{5,7}$ Internal organ involvement includes hepatitis, pneumonitis, myocarditis, pericarditis, nephritis, and colitis. Investigations reveal leukocytosis with eosinophilia and atypical lymphocytes, elevated liver enzymes, proteinuria, and hematuria. Histopathologic features are heterogeneous and non-specific ${ }^{8}$ and usually show perivascular lymphocyte infiltrate in papillary dermis with atypical lymphocytes and spongiosis of epidermis. ${ }^{9}$ The European Registry of Severe Cutaneous Adverse Reaction Study Group introduced the RegiSCAR scoring system to classify as "no", "possible", "probable", or "definite" case of DRESS syndrome. $^{10}$

Treatment involves withdrawal of the triggering drug, topical corticosteroid for cutaneous symptoms, and systemic corticosteroid for severe systemic manifestations. Steroids are tapered over 6-8 weeks to prevent relapse. In case of failure of corticosteroid therapy, plasmapheresis and immunosuppressive drugs like cyclosporine, cyclophosphamide, interferon, mycophenolate mofetil, and rituximab are tried. ${ }^{11}$

In our case, the patient presented after 17 days of the introduction of an offending drug (likely cotrimoxazole or piperacillin-tazobactam) with the characteristic signs and symptoms of DRESS syndrome (fever, skin rash, eosinophilia, hepatitis, facial edema). One of the main differential diagnoses was Steven-Johnson syndrome which was ruled out in view of the late manifestation of symptoms after the introduction of the drug and minimal mucosal involvement. RegiSCAR sore was 6 suggestive of a definite diagnosis of DRESS syndrome. Since the child qualified as "definite", and the parents did not consent; a skin biopsy was not done. The symptoms resolved with corticosteroid therapy with normalization of laboratory abnormalities.

Among antimicrobials, vancomycin, cotrimoxazole, ampicillin, dapsone, isoniazid, linezolid, minocycline, and rifampin have been implicated, although very few case reports in pediatric patients are available. Cacoub et al. reviewed the literature of 172 published cases of DRESS from January 1997 to May 2009 and reported one case due to cotrimoxazole and 2 cases due to sulfamethoxazole. ${ }^{3}$

\section{Conclusion}

Being a rare entity in pediatrics, DRESS syndrome is often missed by clinicians. The diagnosis is purely clinical although skin biopsy can be performed as supportive evidence. Prompt withdrawal of the offending drug forms the mainstay of treatment.

\section{Clinical Significance}

Due to the potential severity of DRESS syndrome, it should be considered in any child presenting with fever, skin rash, hepatitis, and lymphadenopathy.

\section{References}

1. Husain Z, Reddy BY, Schwartz RA. DRESS syndrome: part I. clinical perspectives. J Am Acad Dermatol 2013;68(5):693.e1-14. DOI: 10.1016/j.jaad.2013.01.032.

2. Bocquet $H$, Bagot M, Roujeau JC. Drug-induced pseudolymphoma and drug hypersensitivity syndrome (drug rash with eosinophilia and systemic symptoms: DRESS). Semin Cutan Med Surg 1996;15(4):250257. DOI: 10.1016/s1085-5629(96)80038-1.

3. Cacoub P, Musette P, Descamps V, et al. The DRESS syndrome: a literature overview. Am J Med 2011;124(7):588-597. DOI: 10.1016/j. amjmed.2011.01.017.

4. Frieling G, Jessup C, Mihm M. Drug rash with eosinophilia and systemic symptoms. In Diagnostic pathology: non-neoplastic dermatopathology Hall BJ, Hall JC, Cockerell CJ, et al., ed. 1st ed., Amirsys Publishing, Inc; 2012. pp. 10-11.

5. Chiou CC, Yang LC, Hung SI, et al. Clinicopathological features and prognosis of drug rash with eosinophilia and systemic symptoms: a study of 30 cases in Taiwan. J Eur Acad Dermatol Venereol 2008;22(9):1044-1049. DOI: 10.1111/j.1468-3083.2008.02585.x.

6. Bohan KH, Mansuri TF, Wilson NM. Anticonvulsant hypersensitivity syndrome: Implications for pharmaceutical care. Pharmacotherapy 2007;27(10):1425-1439. DOI: 10.1592/phco.27.10.1425.

7. Peyrièreeyrière $\mathrm{H}$, Dereure $\mathrm{O}$, Breton $\mathrm{H}$, et al. Variability in the clinical pattern of cutaneous side-effects of drugs with systemic symptoms: does a DRESS syndrome really exist? Br J Dermatol 2006;155(2):422428. DOI: 10.1111/j.1365-2133.2006.07284.x.

8. Cho YT, Yang CW, Chu CY. Drug reaction with eosinophilia and systemic symptoms (DRESS): an interplay among drugs, viruses, and immune system. Int J Mol Sci. 2017;18(6):1243. DOI: 10.3390/ ijms18061243.

9. Ortonne N, Valeyrie-Allanore L, Bastuji- Garin S, et al. Histopathology of drug rash with eosinophilia and systemic symptoms syndrome: a morphological and phenotypical study. Br J Dermatol 2015;173(1):50. DOI: 10.1111/bjd.13683.

10. Kardaun $\mathrm{SH}$, Sidoroff A, Valeyrie-Allanore L. Variability in the clinical pattern of cutaneous side-effects of drugs with systemic symptoms: does a DRESS syndrome really exist? Br J Dermatol 2007;156(3):609611. DOI: $10.1111 /$ j.1365-2133.2006.07704.x.

11. Husain Z, Reddy BY, Schwartz RA. DRESS syndrome: Part II. Management and therapeutics. J Am Acad Dermatol 2013;68(5):709. e1-9. DOI: 10.1016/j.jaad.2013.01.032. 